\title{
Aberrant MRP14 expression in thyroid follicular cells mediates chemokine secretion through the IL-1//MAPK pathway in Hashimoto's thyroiditis
}

\author{
Xuan Luo', Tingting Zheng ${ }^{1}$, Chaoming Mao ${ }^{1,2}$, Xin Dong ${ }^{1}$, Xiao Mou ${ }^{1}$, Chengcheng Xu' ${ }^{1}$,ingyan Lu', \\ Baocui Liu', Shengjun Wang ${ }^{3}$ and Yichuan Xiao ${ }^{4}$ \\ ${ }^{1}$ Department of Nuclear Medicine, The Affiliated Hospital of Jiangsu University, Zhenjiang, China \\ ${ }^{2}$ Institute of Oncology, The Affiliated Hospital of Jiangsu University, Zhenjiang, China \\ ${ }^{3}$ Department of Laboratory Immunology, Jiangsu University School of Medicine, Zhenjiang, China \\ ${ }^{4}$ Key Laboratory of Stem Cell Biology, Institute of Health Sciences, Shanghai Institutes for Biological Sciences, Chinese Academy of Sciences and Shanghai \\ Jiao Tong University School of Medicine, Shanghai, China
}

Correspondence should be addressed to C Mao: jq1001@ujs.edu.cn

\begin{abstract}
Myeloid-related protein 14 (MRP14) is responsible for inflammatory reactions. However, the correlation between MRP14 and Hashimoto's thyroiditis (HT) is still not clear. In this study, we examined the status of MRP14 in thyroid tissues and sera of HT patients and explored the mechanism of IL-1 $\beta$-mediated regulation of MRP14 expression, as well as the effects of MRP14 on pro-inflammatory chemokine secretion in thyroid follicular cells (TFCs), to elucidate the role of MRP14 in HT development. Our results showed dramatically increased MRP14 expression in thyroid tissues and sera from HT patients. In addition, IL-1 $\beta$ significantly promoted the expression of MRP14 in TFCs, which was mediated by activation of the MAPK/NF-кB signalling pathway. More importantly, IL-1 $\beta$ induced the secretion of the chemokines GRO-2, CXCL9 and CCL22, which was dependent on the regulation of MRP14 in TFCs. Therefore, these findings suggested that under pro-inflammatory conditions, TFCs secreted chemokines with the help of MRP14 regulation, which might suggest a potential pathological mechanism of lymphocyte infiltration into the thyroid gland in HT.
\end{abstract}

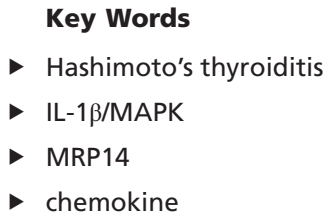

Endocrine Connections (2018) 7, 850-858

\section{Introduction}

Myeloid-related protein 8 (MRP8) and myeloid-related protein 14 (MRP14) are also known as S100A8 and S100A9, which are two members of the S100 protein family that are expressed in the cytosol of monocytes and granulocytes $(1,2)$. A previous study suggested that MRP8 and MRP14 associate with each other to form a heterodimer, which exhibits inflammation modulatory properties (3). MRP14, one subunit of the heterodimer MRP8/MRP14, is locally secreted at high concentrations from immigrated and activated phagocytes at local sites of inflammation. In chronic bronchitis, cystic fibrosis, systemic lupus erythematosus and rheumatoid arthritis, plasma MRP8/MRP14 levels are elevated and can be used as a biomarker $(4,5,6)$. However, the role of the MRP14 homodimer is not clear in Hashimoto's thyroiditis (HT).

HT is characterised by infiltration of thyroidspecific T lymphocytes and other immune cells, thyroid enlargement and fibrosis and progressive destruction of thyrocytes, eventually resulting in hypothyroidism (7). Although recent studies show that an increase in the incidence of HT involves many factors, including genetic susceptibility, inflammation, smoking, excess iodine intake and infection $(8,9,10,11,12,13)$, the pathogenesis of HT remains unclear. During HT pathogenesis, the cytokine http://www.endocrineconnections.org https://doi.org/10.1530/EC-18-0019 (c) 2018 The authors Published by Bioscientifica Ltd

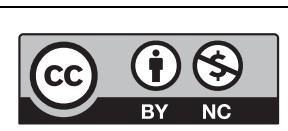

This work is licensed under a Creative Commons Attribution-NonCommercial 4.0 International License. 
IL-1 has been reported to stimulate thyroid follicular cell (TFC) proliferation and produce other pro-inflammatory cytokines, such as IL-6 and IL-8, which in turn mediate TFC destruction $(14,15,16,17)$.

In recent years, numerous studies, both experimental and clinical, demonstrated that pro-inflammatory chemokines, such as MIP-1, CCL2, CCL5, CXCL9, CXCL10 and CCL17, critically regulate the initiation and maintenance of the inflammatory process, which ultimately leads to autoimmune thyroid diseases such as HT and Graves' disease $(18,19,20,21,22,23)$. In the present study, for the first time, we demonstrated the potential role of MRP14 in HT pathogenesis; MRP14 mediated TFC-derived chemokine secretion through the IL-1 $\beta /$ MAPK pathway.

\section{Materials and methods}

\section{Cell culture and samples}

The human thyroid follicular cell line Nthy-ori 3-1 from the European Collection of Animal Cell Cultures was cultivated in RPMI-1640 (Gibco) supplemented with 10\% foetal bovine serum and $2 \mathrm{mM}$ L-glutamine (Biological Industries, Kibbutz Beit Haemek, Israel). Thyroid glands were obtained from 6 patients with HT who underwent thyroidectomy. HT diagnosis was made based on clinical evaluations and Japanese guidelines as described previously $(24,25)$. Thyroid tissues from 5 patients with a simple goitre were used as controls based on clinical evaluations and laboratory findings. All samples were obtained in accordance with the regulations and approval of the Institutional Review Board of the Affiliated Hospital of Jiangsu University. For all cases, written informed consent forms were obtained from the patients. This study was approved by the Ethics Committee of the Affiliated Hospital of Jiangsu University and conducted in accordance with the guidelines of the Declaration of Helsinki.

\section{Immunohistochemistry (IHC)}

Thyroid samples were fixed in 10\% neutralised formalin, embedded in paraffin, cut into $4 \mu \mathrm{m}$ sections and mounted on slides. After deparaffinisation and rehydration, antigen retrieval was performed by boiling samples in $10 \mathrm{mmol} / \mathrm{L}$ citrate buffer ( $\mathrm{pH}$ 6.0) for $10 \mathrm{~min}$ and then washing the slides with phosphate-buffered saline (PBS). Sections were blocked with $2 \%$ bovine serum albumin in PBS for $30 \mathrm{~min}$

$$
\text { http://www.endocrineconnections.org }
$$

and then incubated with mouse anti-human MRP14 (Santa Cruz) and IL-1 $\beta$ (Santa Cruz) antibodies overnight at $4^{\circ} \mathrm{C}$. After three washes with PBS, the sections were treated with the corresponding streptavidin peroxidase-conjugated secondary antibody (Maixin Biotechnology Co., Ltd., Fuzhou, China). Tissue sections were then counterstained with 3,3'-diaminobenzidine and haematoxylin and observed under an optical microscope.

\section{Immunoblots}

Total protein was extracted from cell lines using RIPA (50 mM Tris-HCL, pH 7.4, 150 mM NaCL, 1\% NP-40, 0.5\% Na-deoxycholate, $1 \mathrm{mM}$ EDTA). Protein concentration was determined using a Bradford protein concentration kit (Sigma). First, the protein extracts were subjected to electrophoresis on $10 \%$ acrylamide gels by SDS-PAGE and then transferred onto a polyvinylidene difluoride membrane (Merck Millipore). After blocking for $1 \mathrm{~h}$ in 5\% skim milk powder, the membranes were incubated with specific primary antibodies, followed by HRP-conjugated secondary antibodies. The signals were detected using Pierce ECL-plus substrate (Thermo Fisher Scientific) and scanned with the ChemiScope series (Clinx, Shanghai, China). Images were analysed using AlphaView software (AIC, Santa Clara, CA, USA), and the results of quantitative analyses are presented graphically.

\section{Serum MRP14 detection}

The sera of HT patients $(n=20)$ and healthy controls $(n=20)$ were collected from the Affiliated Hospital of Jiangsu University. Serum samples were diluted 100-fold due to high endogenous concentrations, and then, the serum protein was concentrated by using the methanolchloroform precipitation method. Briefly, we added $600 \mu \mathrm{L}$ of methanol followed by $150 \mu \mathrm{L}$ of chloroform to the $600 \mu \mathrm{L}$ diluted serum samples and mixed thoroughly by vortexing. We centrifuged the samples at $13,000 \mathrm{rpm}$ for $10 \mathrm{~min}$ and carefully aspirated the upper methanol layer without disturbing the protein boundary layer. The samples were then combined with $450 \mu \mathrm{L}$ of methanol and mixed well by vortexing. We recentrifuged the sample at $13,000 \mathrm{rpm}$ for $10 \mathrm{~min}$. Then, the supernatant methanol was removed completely, and the sample was air dried for approximately $5 \mathrm{~min}$ and mixed with $20 \mu \mathrm{L}$ $1 \times$ protein loading buffer (with $10 \%$ fresh $1 \mathrm{M}$ DTT). After the samples were boiled at $95^{\circ} \mathrm{C}$ for $5 \mathrm{~min}$, they were cooled on ice. The protein was then prepared for immunoblot analysis.

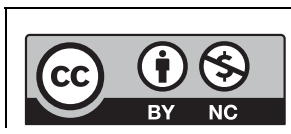

This work is licensed under a Creative Commons Attribution-NonCommercial 4.0 International License. 


\section{Immunofluorescence staining}

Cells were grown on poly-D-lysine-coated coverslips in RPMI 1640 medium containing 10\% FBS. Before treatment, Nthy-ori 3-1 cells were starved overnight and then treated with IL-1 $\beta$ 20 ng/mL (Peprotech, Rocky Hill, NJ, USA) at the indicated time points. After stimulation, the cells were fixed for $15 \mathrm{~min}$ with $4 \%$ paraformaldehyde and permeabilised for $5 \mathrm{~min}$ with PBS containing $0.1 \%$ Triton X-100, and nonspecific binding sites were blocked by incubation with PBS containing 3\% BSA. For immunofluorescence staining, cells were incubated with a mouse monoclonal antibody against MRP14 (1:50) (Santa Cruz), and FITC-conjugated anti-mouse IgG (1:400, Beyotime, Shanghai, China) was used as the secondary antibody. Images were then recorded by fluorescence microscopy (Olympus).

\section{Quantitative real-time PCR (qPCR)}

Total RNA was extracted from the thyroid follicular cell line Nthy-ori 3-1 using TRIzol reagent (Takara) following the manufacturer's instructions. One microgram of RNA was reverse transcribed by a Prime-Script RT reagent Kit (Takara) in a final volume of $20 \mu \mathrm{L}$. The mRNA levels were quantified by using SYBR Premix Ex Taq (Takara) with specific primers as follows: GAPDH, forward 5'-aggtgaaggtcggagtcaac-3', reverse 5'-gggtggaatcatattggaaca-3'; MRP14, forward 5 '-cagctggaacgcaacataga-3', reverse 5'-ccacagccaagacag tttga-3'; GRO-2, forward 5'-ctgcgcccaaaccgaagtcata-3', reverse 5'-ttcaggaacagccaccaataagc-3'; CXCL8, forward 5 '-ctgagagtgattgagagtgg-3', reverse 5'-acaaccctctgcacccag tt-3'; CXCL9, forward 5'-ccaccgagatccttatcgaa-3', reverse 5'-ctaaccg acttggctgcttc-3'; CXCL10, forward 5'-ccacgtgtt gagatcattgc- $3^{\prime}$, reverse $5^{\prime}$-cctctgtgtggtccatcctt-3'; CXCL 16, forward 5'-gggggcagtcaccgcagtcct-3', reverse 5'-aatagcc gggtgtggtggtgagca-3'; CCL22, forward 5'-tgggaggtagttcttc ttttga-3', reverse 5'-ccaagcaaggaggacga-3'.

\section{SiRNA preparation and transfection}

Small interfering RNA molecules targeting MRP14 were synthesised using the GenePharma siRNA Construction Kit. The primers used were as follows: siRNA-hum-MRP14-100, sense template 5'-ccaccaaauacucugugaagtt-3', antisense template $\quad 5^{\prime}$-cuucacagaguauugguggtt-3'; siRNA-humMRP14-267, sense template 5'-gcuucgaggaguucaucautt-3', antisense template $5^{\prime}$-augaugaacuccucgaagctt- 3 '. Nthy-ori 3 - 1 cells were plated in six-well plates at $4 \times 10^{5}$ cells/well, grown for $12 \mathrm{~h}$ and then transfected with siRNA at a (c) 2018 The authors

http://www.endocrineconnections.org https://doi.org/10.1530/EC-18-0019 concentration of $100 \mathrm{nM}$ using lipofectamine (Invitrogen Life Technologies, Inc.) and opti-MEM (Gibco) according to the manufacturer's protocol. MRP14 mRNA expression was examined $48 \mathrm{~h}$ after transfection by qPCR.

\section{Construction of the MRP14 expression plasmid}

The eukaryotic expression plasmids pcDNA3.1 MRP14 and pcDNA3.1 no-load carrier were provided by the GenePharma Company. The plasmid was inserted into competent bacteria with a disinfected and sterilised inoculating loop to obtain plasmid-carrying Escherichia coli, which was then inoculated in the pre-prepared LuriaBertani (LB) solid medium (ampicillin) and incubated overnight at room temperature. Then, a single colony was selected and inoculated into the pre-prepared LB fluid medium $(200 \mathrm{~mL})$ and incubated on a shaking table $(250 \mathrm{rpm})$ overnight $(12-18 \mathrm{~h})$ at $37^{\circ} \mathrm{C}$. Afterwards, the medium was observed to be turbid, and some medium was stored in $25 \%$ glycerol at $-20^{\circ} \mathrm{C}$, and the rest was used for plasmid DNA purification. Plasmid DNA was extracted as per the instructions of the TianGen Plasmid Kit (TianGen Company).

\section{Statistical analysis}

Statistical analysis was performed using GraphPad Prism 6 software (GraphPad Software, Inc.). The descriptive data are expressed as the mean \pm s.E.M. (standard error of the mean), and numerical data between two groups were compared using a two-tailed unpaired $t$-tests. Differences in the mean values of various groups were analysed by using one-way ANOVA with Mann-Whitney $U$ tests. $P<0.05$ was considered statistically significant.

\section{Results}

MRP14 is highly expressed in HT tissues and serum of HT patients

Previous studies have shown an increase of serum MRP14 level in multiple autoimmune diseases (6, 26, 27). In the present study, the MRP14 level in thyroid tissues of HT patients was evaluated. As expected, immunohistochemistry (IHC) analysis indicated that MRP14 protein was highly expressed in HT tissues $(n=6)$. In contrast, the tissues from healthy controls $(n=5)$ expressed very low levels of MRP14 (Fig. 1A). Consistently, we also found that the serum MRP14 protein levels in 
the patients suffering from HT $(n=20)$ were significantly higher than those from the healthy controls $(n=20)$ (Fig. 1B). Therefore, these findings suggested that HT patients expressed abnormal levels of MRP14 protein.

\section{IL-1 $\beta$ induces MRP14 expression in TFCs}

To determine why MRP14 is highly expressed in HT patients, we investigated the induction of MRP14 expression in TFCs by using different pro-inflammatory cytokines that are associated with HT pathogenesis. The Nthy-ori 3-1 TFCs were starved overnight and then stimulated for $4 \mathrm{~h}$ with IL- $1 \beta$, TGF- $\beta$ and TNF- $\alpha$. qPCR results showed that expression of MRP14 was only markedly induced by IL- $1 \beta$ with a maximal effect at $20 \mathrm{ng} / \mathrm{mL}$ (Fig. 2A). Therefore, we used $20 \mathrm{ng} / \mathrm{mL}$ IL-1 $\beta$ for the subsequent experiments. In concert with the qPCR data, immunofluorescence assays also confirmed the IL-1 $\beta$-mediated induction of MRP14 protein expression in Nthy-ori 3-1 cells (Fig. 2B). Accordingly, IHC assays suggested that IL-1 $\beta$ expression was much higher in HT tissues $(n=4)$ than in healthy controls $(n=4)$ (Fig. 2C). Collectively, our data suggested that increased IL-1 $\beta$ in thyroid tissues was responsible for the elevated expression of MRP14 during HT pathogenesis.

\section{IL-1 $\beta$ mediates MAPK and NF-кB in TFCs}

To further determine the molecular mechanism of IL-1 $\beta$ induced MRP14 expression, we examined IL-1 $\beta$-induced MAPK and NF- $\kappa$ B activation in Nthy-ori 3-1 cells. As shown in Fig. 3A, we observed that IL-1 $\beta$ treatment significantly induced the activation of MAPK, characterised by dramatically increased phosphorylation of p38, ERK and JNK. Additionally, IL-1 $\beta$-induced NF-кB activation was significantly enhanced as expected (Fig. 3B). Immunoblot results revealed increased phosphorylation of both p65 and $\mathrm{I} \kappa \mathrm{B} \alpha$ along with the degradation of IкB $\alpha$ after IL- $1 \beta$ stimulation, with a maximum phosphorylation at 15 and $30 \mathrm{~min}$ of treatment. These results suggested that activation of MAPK and NF- $\mathrm{B}$ is required for IL- $1 \beta$ induced MRP14 in Nthy-ori 3-1 cells.

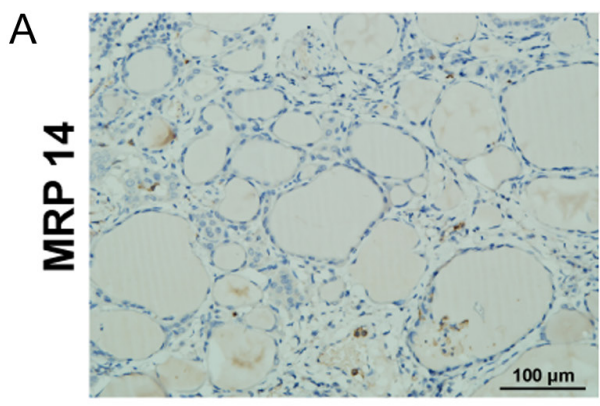

Control

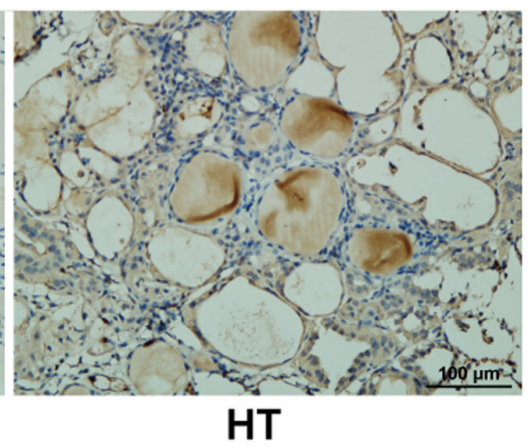

HT

B

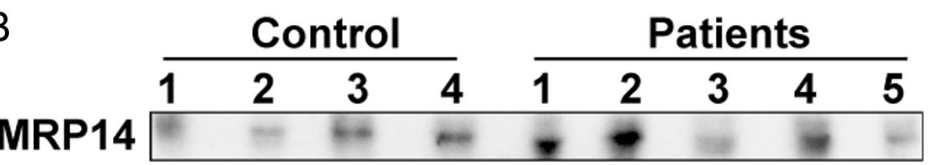

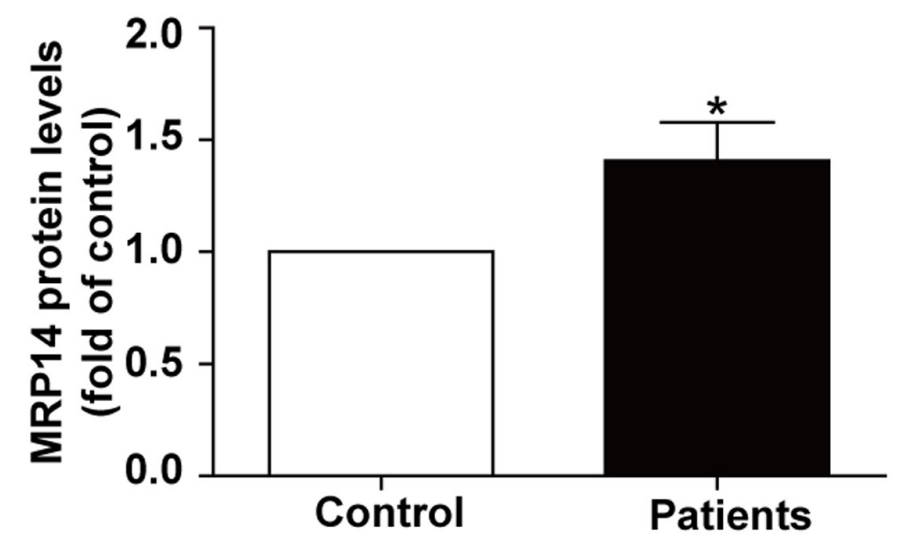

\section{Figure 1}

MRP14 expression in the thyroid tissues and sera of Hashimoto's thyroiditis (HT) patients. (A) Representative results of MRP14 immunohistochemical staining in HT tissues $(n=6)$ and control tissues $(n=5)$ are shown. 'Control' indicates tissues from patients with simple goitre of the thyroid. Brown regions represent positive expression (original magnification, $\times 200$; scale bars, $100 \mu \mathrm{m})$. (B) Serum MRP14 levels of HT $(n=20)$ and healthy controls $(n=20)$ were analysed by immunoblots. Representative immunoblotting results of MRP14 (upper panel) are shown. The results of immunoblot quantification from all samples are shown (lower panel). Significant differences and $P$ values are calculated by unpaired $t$-tests. ${ }^{*} P<0.05$ vs controls.

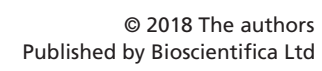

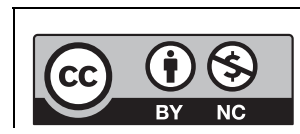
This work is licensed under a Creative Commons
Attribution-NonCommercial 4.0 International License. 
A

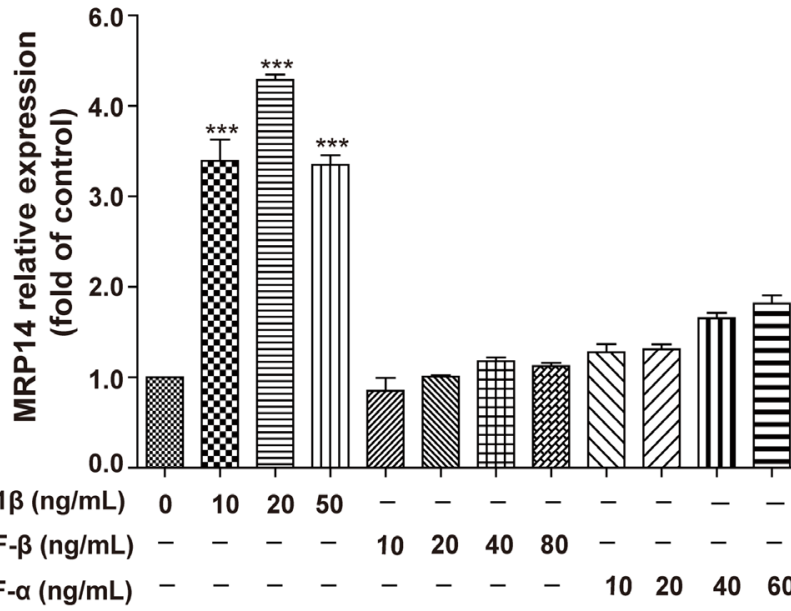

C

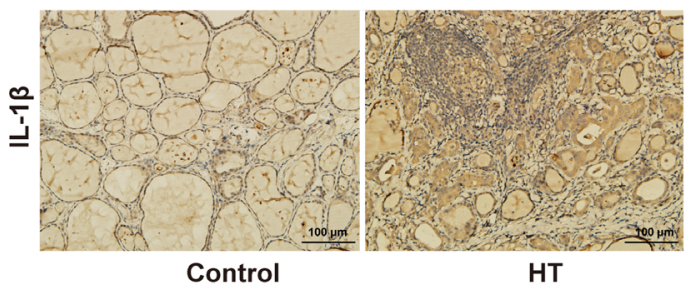

B

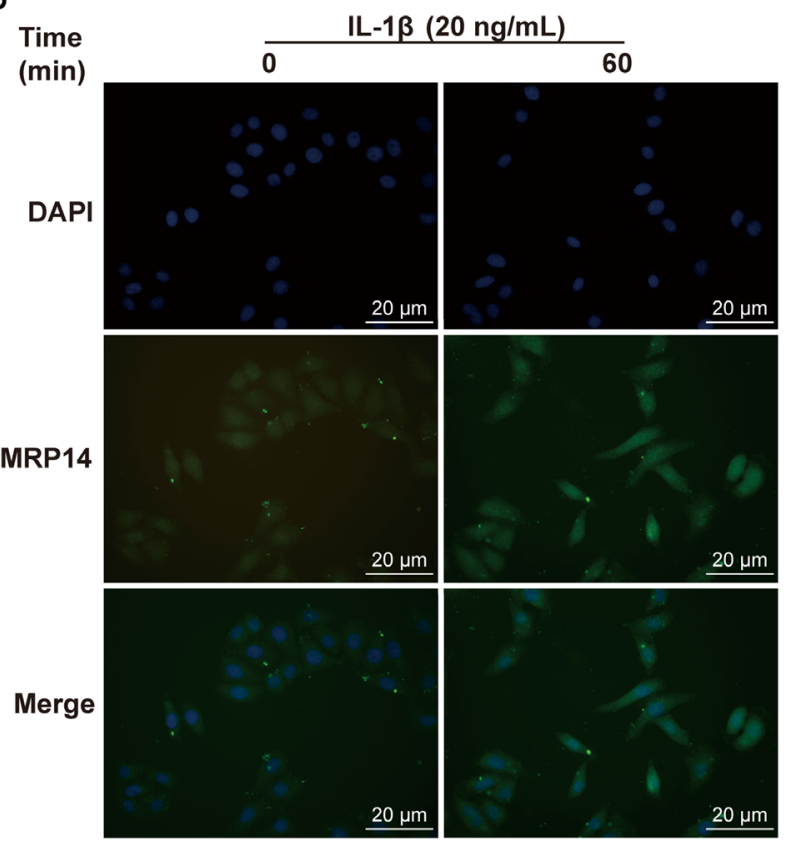

Figure 2

IL-1 $\beta$ induces MRP14 expression in Nthy-ori 3-1 cells. (A) Nthy-ori 3-1 cells were starved overnight and then incubated with gradient concentrations of IL-1 $\beta$, TGF- $\beta$ and TNF- $\alpha$ for $4 \mathrm{~h}$, and cells were harvested for quantitative real-time PCR (qPCR). The results shown are representative of three replicates (left upper panel). (B) Nthy-ori 3-1 cells were starved overnight and then incubated with IL-1 $\beta 20 \mathrm{ng} / \mathrm{mL}$. MRP14 levels were detected by

immunofluorescence staining (original magnification, $\times 400$; scale bars, $20 \mu \mathrm{m}$ ). (C) Representative results of IL- $1 \beta$ immunohistochemical staining in HT tissues $(n=4)$ and control tissues $(n=4)$ are shown (original magnification, $\times 200 ;$ scale bars, $100 \mu \mathrm{m})$. Significant differences and $P$ values were calculated by one-way ANOVA and the Mann-Whitney $U$ tests. $* * * P<0.001$ vs controls.

MRP14 regulates the expression of the chemokines

\section{GRO-2, CXCL9 and CCL22 in TFCs}

To determine the effect of IL-1 $\beta$-induced up-regulation of MRP14 in Nthy-ori 3-1 cells, we examined expression of pro-inflammatory chemokines in response to IL-1 $\beta$. The results showed that the expression levels of multiple proinflammatory chemokines, such as GRO-2, CXCL9 and CCL22, were increased in the presence of IL-1 $\beta$, but not CXCL8 and CXCL16 (Fig. 4A), while IFN- $\gamma(500 \mathrm{U} / \mathrm{mL})$ induced GRO-2, CXCL10 and CXCL16, but not CXCL8 CXCL9 and CCL22 (Fig. 4B), suggesting that different inflammatory cytokines exerted different effects on the secretion of chemokines in TFCs. To examine the correlation between IL-1 $\beta$-induced MRP14 and these chemokine expressions, small interfering RNA molecules targeting MRP14 transcripts were used to knock down MRP14 expression in Nthy-ori 3-1 cells. We observed a reduction of approximately 50\% in MRP14 mRNA expression when siRNA-MRP14 was transfected into Nthyori 3-1 cells for $48 \mathrm{~h}$ (Fig. 4C). Interestingly, we found that MRP14 silencing significantly inhibited the expression

http://www.endocrineconnections.org https://doi.org/10.1530/EC-18-0019

(c) 2018 The authors Published by Bioscientifica Ltd levels of GRO-2, CXCL9 and CCL22 (Fig. 4D-4F). In contrast, overexpression of MRP14 in Nthy-ori 3-1 cells significantly enhanced the expression levels of these pro-inflammatory chemokines (Fig. 4D, E and F). These results suggested that MRP14 mediated IL-1 $\beta$ induction of GRO-2, CXCL9 and CCL22.

\section{Discussion}

Recent evidence has shown the involvement of cytokines and chemokines in the pathogenesis of autoimmune thyroiditis. Infiltrated T helper 1 (Th1) lymphocytes in thyroid tissue are responsible for the enhanced production of IFN- $\gamma$, TNF- $\alpha$, IL-6, IL-1 and IL-23 (13). These cytokines in turn may induce chemokine secretion of TFCs. Recent evidence has shown that IFN- $\gamma$ and TNF- $\alpha$ induce the secretion of CXCL8, CXCL9, CXCL10 and CXCL11 in primary TFCs $(28,29,30)$. In addition, our results showed that IFN- $\gamma$ induced the secretion of GRO2, CXCL10 and CXCL16 in the TFC line Nthy-ori 3-1, suggesting that there was a difference in the secretion of chemokine

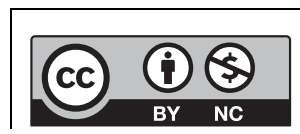

This work is licensed under a Creative Commons Attribution-NonCommercial 4.0 International License. 

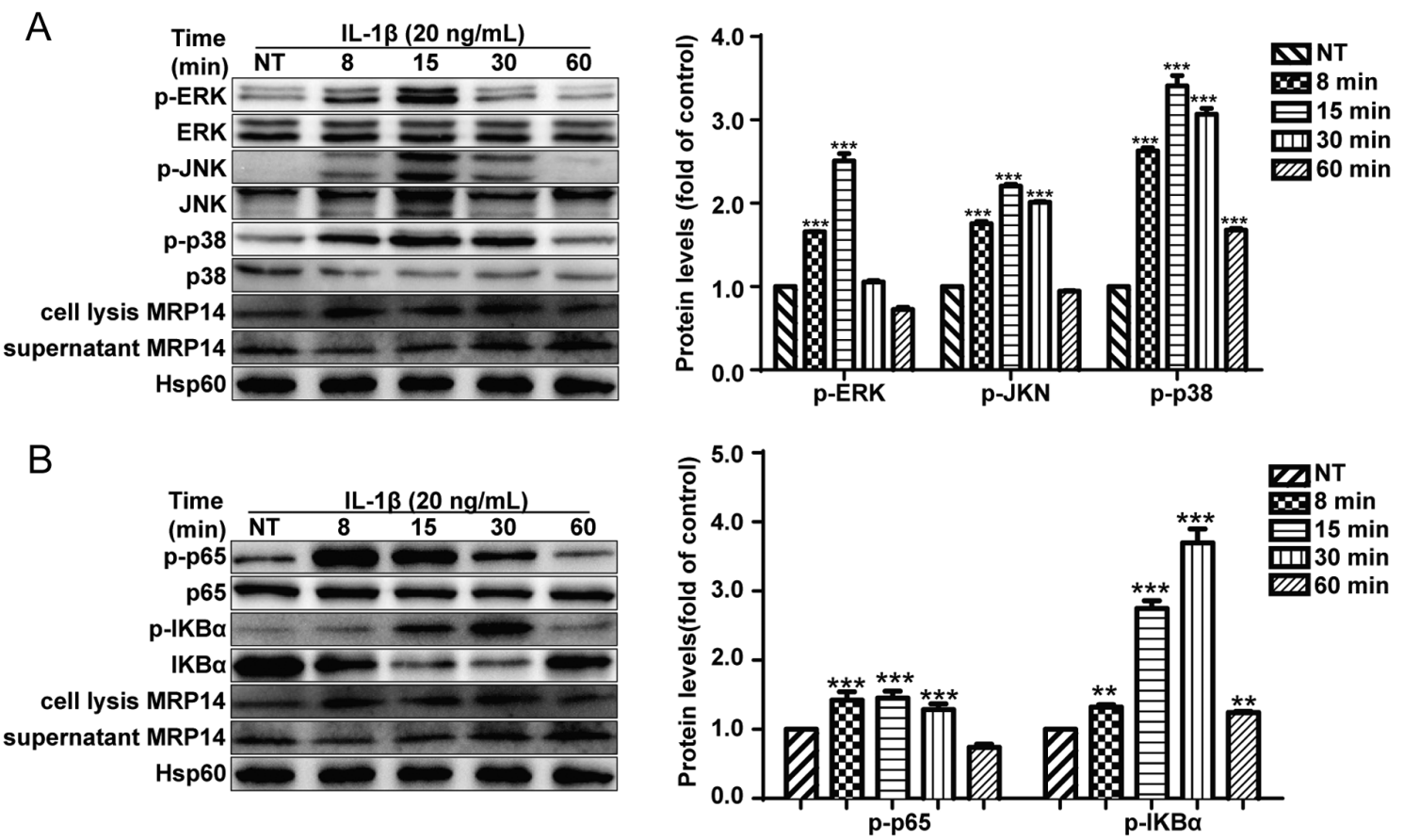

Figure 3

Effect of IL-1 $\beta$ on the MAPK and NF-KB signalling pathways. Lysates of cells treated with IL-1 $20 \mathrm{ng} / \mathrm{mL}$ for the indicated times were assessed. (A) p-ERK1/2, p-p38, p-JNK (indicators of MAPK activation) and (B) p-p65, p-IKBa (an indicator of NF-KB activation) were incubated with corresponding antibodies by immunoblotting, with Hsp 60 as the loading control. Data are the mean \pm s.E.M. of three independent experiments (right panel). Significant differences and $P$ values were calculated by one-way ANOVA and Mann-Whitney $U$ tests. $* * P<0.01, * * * P<0.001$ vs controls.

profiles between primary TFCs and the TFC line. Notably, an early study reported increased expression levels of CCL2, CXCL8, CXCL9, CXCL13, CCL21 and CCL22 in autoimmune thyroid disease tissues (31), indicating that besides IFN $\gamma$-induced chemokines, other cytokine pathways induced the production of some chemokines. In this study, we confirmed that the cytokine IL-1 $\beta$ mainly induced the expression of GRO-2 (CCL2), CCL22 and CXCL9 in TFCs, but not CXCL8 and CXCL16, which was different from the IFN- $\gamma$-inducible chemokine profile. Taken together, these results suggested that inducible chemokine profiles from TFCs were dependent on the type of cytokine used, which was affected by the duration of activation and activity, pharmacological treatment and patients at different stages of $\operatorname{HT}(32,33,34)$.

The mechanism of IFN- $\gamma$-inducible chemokine is clear, but that of IL-1 $\beta$ is not. It is reported that MRP8/MRP14 expression is related to pro-inflammatory chemokines, such as IL-8, Gro- $\alpha$ and MCP-1, which promote leukocyte recruitment through chemoattractive effects (35) and are induced by LPS, TNF- $\alpha$ or IL- $1 \beta$ in myeloid and other nonmyeloid cell types, such as monocytes, neutrophils, human gingival epithelial cells and murine microvascular endothelial cells $(36,37,38,39)$. A previous study reported that an increase of MRP8/MRP14 expression was

$\begin{array}{lr}\text { http://www.endocrineconnections.org } & \text { () } 2018 \text { The authors } \\ \text { https://doi.org/10.1530/EC-18-0019 } & \text { Published by Bioscientifica Ltd }\end{array}$

found in autoimmune thyroid disease (40). Interestingly, consistent with these findings, we also found that the level of MRP14 homodimer expression, but not the MRP8/MRP14 heterodimer, was elevated not only in the sera but also in the thyroid tissues from HT patients. This is the first report on MRP14 levels in HT patients, and the abnormal expression of MRP14 suggested that MRP14, as a biomarker of inflammation, participates in the pathogenesis of HT. Importantly, IL-1 $\beta$ was also highly expressed in the tissues of the HT patients, suggesting that there is an interaction between MRP14 and IL-1 $\beta$ in the development of HT. Notably, our results showed that IL-1 $\beta$ induced the expression of not only chemokines in TFCs but also MRP14, and further study demonstrated that IL-1 $\beta$-induced chemokine profiles were mediated by MRP14 through knockdown and overexpression of the MRP14 gene in TFCs, which is consistent with previous studies (41). In addition, IL-1 $\beta$ affected almost every cell type in the body and provokes inflammation in all tissues through the MAPK and NF-кB pathways $(42,43)$. In line with these findings, we demonstrated that IL1 $\beta$-induced MRP14 expression was dependent on the MAPK and NF- $\kappa \mathrm{B}$ signalling pathways.

Numerous works demonstrate that chemokines (GRO2, CXCL9 and CCL22) can increase the migration

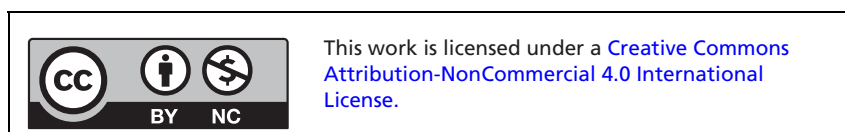


A

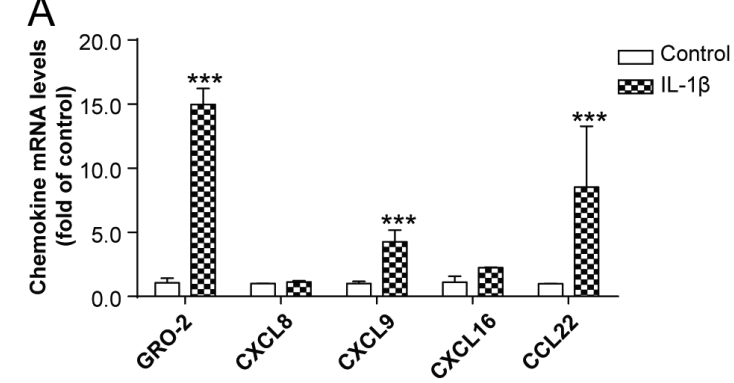

B

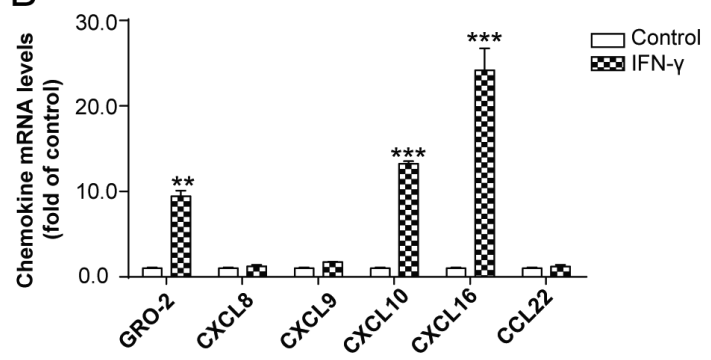

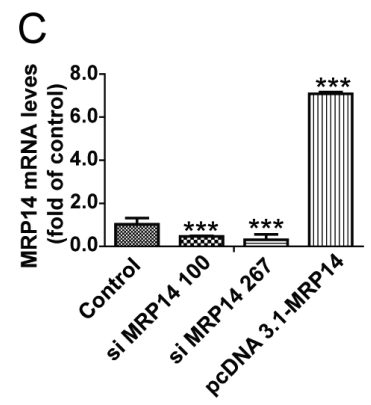

D

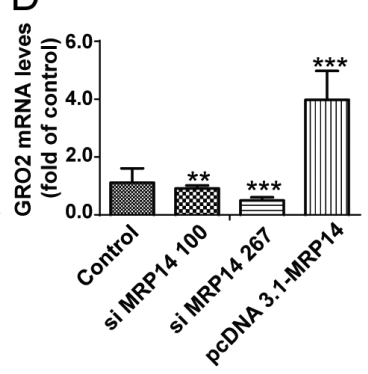

E

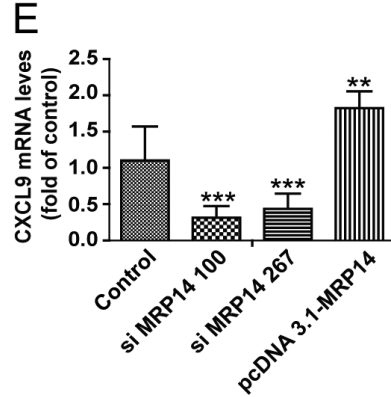

$F$

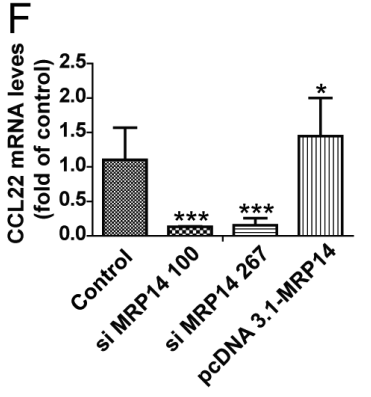

Figure 4

The expression of MRP14 is closely related to the expression of chemokines. (A) Nthy-ori 3-1 cells were treated with IL-1 $\beta$ ( $20 \mathrm{ng} / \mathrm{mL})$ for $4 \mathrm{~h}$, and the mRNA levels of GRO2, CXCL8, CXCL9, CXCL16 and CCL22 were determined by qPCR. (B) Nthy-ori 3-1 cells were treated with IFN- $\gamma$ (500 U/mL) for $4 \mathrm{~h}$, and the mRNA levels of GRO2, CXCL8, CXCL9, CXCL10, CXCL16 and CCL22 were determined by qPCR. Nthy-ori 3-1 cells were transiently transfected with the siRNA targeting MRP14, the plasmid pcDNA3.1-MRP14 or control for 48h. MRP14 (C), GRO2 (D), CXCL9 (E) and CCL22 (F) mRNA levels were detected by qPCR. Data are the mean \pm S.E.M. of three independent experiments. Significant differences and $P$ values were calculated by one-way ANOVA and the Mann-Whitney $U$ tests. ${ }^{*} P<0.05, * * P<0.01, * * * P<0.001$ vs controls.

of lymphocytes, monocyte and neutrophils to the thyroid gland, thus perpetuating the disease (44). Therefore, we speculated that under inflammatory circumstances from HT, abnormal expression of pro-inflammatory chemokines by the IL-1 $\beta /$ MRP14-mediated pathway led to lymphocyte infiltration into the lesion thyroid gland and HT development.

Like any other study, this study has its limitations. For example, the underlying molecular mechanism of MRP14 regulation of pro-inflammatory chemokines is not clear. Moreover, our results were determined only from a TFC line, not primary thyroid cells. In addition, this study mainly focused on MRP14, not MRP8/MRP14. Whether the MRP14 homodimer has a higher clinical value than the MRP8/MRP14 heterodimer needs to be explored. In conclusion, we provided evidence that IL- $1 \beta$ induces the production of chemokines through up-regulated MRP14 expression in a MAPK/NF- $\kappa$ B pathway-dependent manner, which might provide a potential mechanism of HT pathogenesis by regulating the expression of chemokines in TFCs.

\section{Declaration of interest}

The authors declare that there is no conflict of interest that could be perceived as prejudicing the impartiality of the research reported.

http://www.endocrineconnections.org https://doi.org/10.1530/EC-18-0019

(C) 2018 The authors Published by Bioscientifica Ltd

\section{Funding}

This work was supported by grants from the National Natural Science Foundation of China (No. 81370889) and Jiangsu Province key research and development program (No. BE20161727).

\section{References}

1 Dale I, Fagerhol MK \& Naesgaard I. Purification and partial characterization of a highly immunogenic human leukocyte protein, the L1 antigen. European Journal of Biochemistry 1983134 1-6. (https://doi.org/10.1111/j.1432-1033.1983.tb07522.x)

2 Nacken W, Roth J, Sorg C \& Kerkhoff C. S100A9/S100A8: myeloid representatives of the $\mathrm{S} 100$ protein family as prominent players in innate immunity. Microscopy Research and Technique $2003 \mathbf{6 0}$ 569-580. (https://doi.org/10.1002/jemt.10299)

3 Srikrishna G. S100A8 and S100A9: new insights into their roles in malignancy. Journal of Innate Immunity 20124 31-40. (https://doi. org/10.1159/000330095)

4 Brun JG, Jonsson R \& Haga HJ. Measurement of plasma calprotectin as an indicator of arthritis and disease activity in patients with inflammatory rheumatic diseases. Journal of Rheumatology 199421 733-738.

5 Roth J, Teigelkamp S, Wilke M, Grun L, Tummler B \& Sorg C. Complex pattern of the myelo-monocytic differentiation antigens MRP8 and MRP14 during chronic airway inflammation. Immunobiology 1992186 304-314. (https://doi.org/10.1016/S01712985(11)80259-7)

6 van Bon L, Cossu M, Loof A, Gohar F, Wittkowski H, Vonk M, Roth J, van den Berg W, van Heerde W, Broen JC, et al. Proteomic analysis of plasma identifies the Toll-like receptor agonists S100A8/A9 as a

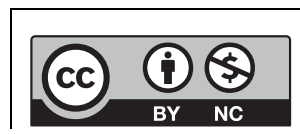

This work is licensed under a Creative Commons Attribution-NonCommercial 4.0 International License. 
novel possible marker for systemic sclerosis phenotype. Annals of the Rheumatic Diseases 201473 1585-1589. (https://doi.org/10.1136/ annrheumdis-2013-205013)

7 Weetman AP. Autoimmune thyroid disease: propagation and progression. European Journal of Endocrinology 2003148 1-9. (https:// doi.org/10.1530/eje.0.1480001)

8 Carle A, Bulow Pedersen I, Knudsen N, Perrild H, Ovesen L, Banke Rasmussen L, Jorgensen T \& Laurberg P. Smoking cessation is followed by a sharp but transient rise in the incidence of overt autoimmune hypothyroidism - a population-based, case-control study. Clinical Endocrinology 201277 764-772. (https://doi. org/10.1111/j.1365-2265.2012.04455.x)

9 Caselli E, Zatelli MC, Rizzo R, Benedetti S, Martorelli D, Trasforini G, Cassai E, degli Uberti EC, Di Luca D \& Dolcetti R. Virologic and immunologic evidence supporting an association between HHV-6 and Hashimoto's thyroiditis. PLoS Pathogens 20128 e1002951. (https://doi.org/10.1371/journal.ppat.1002951)

10 Luo Y, Kawashima A, Ishido Y, Yoshihara A, Oda K, Hiroi N, Ito T, Ishii $\mathrm{N} \&$ Suzuki K. Iodine excess as an environmental risk factor for autoimmune thyroid disease. International Journal of Molecular Sciences 201415 12895-12912. (https://doi.org/10.3390/ijms150712895)

11 McLeod DS, Caturegli P, Cooper DS, Matos PG \& Hutfless S. Variation in rates of autoimmune thyroid disease by race/ethnicity in US military personnel. JAMA 2014311 1563-1565. (https://doi. org/10.1001/jama.2013.285606)

12 Xu C, Wu F, Mao C, Wang X, Zheng T, Bu L, Mou X, Zhou Y, Yuan G, Wang S, et al. Excess iodine promotes apoptosis of thyroid follicular epithelial cells by inducing autophagy suppression and is associated with Hashimoto thyroiditis disease. Journal of Autoimmunity 201675 50-57. (https://doi.org/10.1016/j.jaut.2016.07.008)

13 Zheng T, Xu C, Mao C, Mou X, Wu F, Wang X, Bu L, Zhou Y, Luo X, $\mathrm{Lu} \mathrm{Q}$, et al. Increased interleukin-23 in Hashimoto's thyroiditis disease induces autophagy suppression and reactive oxygen species accumulation. Frontiers in Immunology 20189 96. (https://doi. org/10.3389/fimmu.2018.00096)

14 Diamant M, Kayser L, Rasmussen AK, Bech K \& Feldt-Rassmussen U. Interleukin- 6 production by thyroid epithelial cells. Enhancement by interleukin-1. Autoimmunity 199111 21-26. (https://doi. org/10.3109/08916939108994704)

15 El Btaouri H, Rath G, Morjani H, Schneider C, Petitfrere E, Antonicelli F \& Martiny L. Interleukin-1beta-induced apoptosis through adenylyl cyclase and ERK1/2 inhibition in primary cultured thyroid cells. Biochemical and Biophysical Research Communications 2006339 469-476. (https://doi.org/10.1016/j.bbrc.2005.10.213)

16 Mine M, Tramontano D, Chin WW \& Ingbar SH. Interleukin-1 stimulates thyroid cell growth and increases the concentration of the c-myc proto-oncogene mRNA in thyroid follicular cells in culture. Endocrinology 1987120 1212-1214. (https://doi.org/10.1210/endo120-3-1212)

17 Rebuffat SA, Kammoun-Krichen M, Charfeddine I, Ayadi H, Bougacha-Elleuch N \& Peraldi-Roux S. IL-1beta and TSH disturb thyroid epithelium integrity in autoimmune thyroid diseases. Immunobiology 2013218 285-291. (https://doi.org/10.1016/j. imbio.2012.05.016)

18 Ferrer-Francesch X, Caro P, Alcalde L, Armengol MP, Ashhab Y, LucasMartin A, Martinez-Caceres EM, Juan M \& Pujol-Borrell R. One-tubePCR technique for CCL2, CCL3, CCL4 and CCL5 applied to fine needle aspiration biopsies shows different profiles in autoimmune and non-autoimmune thyroid disorders. Journal of Endocrinological Investigation 200629 342-349. (https://doi.org/10.1007/BF03344106)

19 Garcia-Lopez MA, Sancho D, Sanchez-Madrid F \& Marazuela M. Thyrocytes from autoimmune thyroid disorders produce the chemokines IP-10 and Mig and attract CXCR3+ lymphocytes. Journal of Clinical Endocrinology and Metabolism 200186 5008-5016. (https:// doi.org/10.1210/jcem.86.10.7953)
20 Hiratsuka I, Itoh M, Yamada H, Yamamoto K, Tomatsu E, Makino M, Hashimoto S \& Suzuki A. Simultaneous measurement of serum chemokines in autoimmune thyroid diseases: possible role of IP-10 in the inflammatory response. Endocrine Journal 201562 1059-1066. (https://doi.org/10.1507/endocrj.EJ15-0448)

21 Inukai Y, Momobayashi A, Sugawara N \& Aso Y. Changes in expression of T-helper (Th) 1- and Th2-associated chemokine receptors on peripheral blood lymphocytes and plasma concentrations of their ligands, interferon-inducible protein-10 and thymus and activation-regulated chemokine, after antithyroid drug administration in hyperthyroid patients with Graves' disease. European Journal of Endocrinology 2007156 623-630. (https://doi. org/10.1530/EJE-07-0019)

22 Kimura H \& Caturegli P. Chemokine orchestration of autoimmune thyroiditis. Thyroid 200717 1005-1011. (https://doi.org/10.1089/ thy.2007.0267)

23 Romagnani P, Rotondi M, Lazzeri E, Lasagni L, Francalanci M, Buonamano A, Milani S, Vitti P, Chiovato L, Tonacchera M, et al. Expression of IP-10/CXCL10 and MIG/CXCL9 in the thyroid and increased levels of IP-10/CXCL10 in the serum of patients with recent-onset Graves' disease. American Journal of Pathology 2002161 195-206. (https://doi.org/10.1016/S0002-9440(10)64171-5)

24 Chen MP, Chung FM, Chang DM, Tsai JC, Huang HF, Shin SJ \& Lee YJ. Elevated plasma level of visfatin/pre-B cell colony-enhancing factor in patients with type 2 diabetes mellitus. Journal of Clinical Endocrinology and Metabolism 200691 295-299. (https://doi. org/10.1210/jc.2005-1475)

25 Liu H, Zheng T, Mao Y, Xu C, Wu F, Bu L, Mou X, Zhou Y, Yuan G, Wang S, et al. gammadelta Tau cells enhance B cells for antibody production in Hashimoto's thyroiditis, and retinoic acid induces apoptosis of the gammadelta Tau cell. Endocrine 201651 113-122. (https://doi.org/10.1007/s12020-015-0631-9)

26 Lin JF, Chen JM, Zuo JH, Yu A, Xiao ZJ, Deng FH, Nie B \& Jiang B. Meta-analysis: fecal calprotectin for assessment of inflammatory bowel disease activity. Inflammatory Bowel Diseases 201420 1407-1415. (https://doi.org/10.1097/MIB.0000000000000057)

27 Sridhar S, Al-Moallem B, Kamal H, Terrile M \& Stallings RL. New insights into the genetics of neuroblastoma. Molecular Diagnosis and Therapy 201317 63-69.

28 Rotondi M, Coperchini F, Pignatti P, Sideri R, Groppelli G, Leporati P, La Manna L, Magri F, Mariotti S \& Chiovato L. Interferon-gamma and tumor necrosis factor-alpha sustain secretion of specific CXC chemokines in human thyrocytes: a first step toward a differentiation between autoimmune and tumor-related inflammation? Journal of Clinical Endocrinology and Metabolism 201398 308-313. (https://doi. org/10.1210/jc.2012-2555)

29 Rotondi M \& Chiovato L. The chemokine system as a therapeutic target in autoimmune thyroid diseases: a focus on the interferon-gamma inducible chemokines and their receptor. Current Pharmaceutical Design 201117 3202-3216. (https://doi. org/10.2174/138161211798157559)

30 Antonelli A, Ferrari SM, Frascerra S, Pupilli C, Mancusi C, Metelli MR, Orlando C, Ferrannini E \& Fallahi P. CXCL9 and CXCL11 chemokines modulation by peroxisome proliferator-activated receptor-alpha agonists secretion in Graves' and normal thyrocytes. Journal of Clinical Endocrinology and Metabolism 201095 E413-E420. (https://doi.org/10.1210/jc.2010-0923)

31 Antonelli A, Ferrari SM, Corrado A, Di Domenicantonio A \& Fallahi P. Autoimmune thyroid disorders. Autoimmunity Reviews 2015 14 174-180. (https://doi.org/10.1016/j.autrev.2014.10.016)

32 Rotondi M, Chiovato L, Romagnani S, Serio M \& Romagnani P. Role of chemokines in endocrine autoimmune diseases. Endocrine Reviews 200728 492-520. (https://doi.org/10.1210/er.2006-0044)

33 Antonelli A, Rotondi M, Fallahi P, Romagnani P, Ferrari SM, Ferrannini E $\&$ Serio M. Age-dependent changes in CXC chemokine ligand 10 serum http://www.endocrineconnections.org

https://doi.org/10.1530/EC-18-0019 (c) 2018 The authors Published by Bioscientifica Ltd

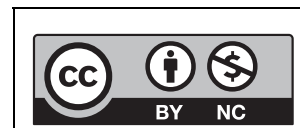

This work is licensed under a Creative Commons Attribution-NonCommercial 4.0 International License. 
levels in euthyroid subjects. Journal of Interferon and Cytokine Research 200525 547-552. (https://doi.org/10.1089/jir.2005.25.547)

34 Antonelli A, Fallahi P, Rotondi M, Ferrari SM, Romagnani P, Grosso M, Ferrannini E \& Serio M. Increased serum CXCL10 in Graves' disease or autoimmune thyroiditis is not associated with hyper- or hypothyroidism per se, but is specifically sustained by the autoimmune, inflammatory process. European Journal of Endocrinology 2006154 651-658. (https://doi.org/10.1530/eje.1.02137)

35 Viemann D, Strey A, Janning A, Jurk K, Klimmek K, Vogl T, Hirono K, Ichida F, Foell D, Kehrel B, et al. Myeloid-related proteins 8 and 14 induce a specific inflammatory response in human microvascular endothelial cells. Blood 2005105 2955-2962. (https://doi. org/10.1182/blood-2004-07-2520)

36 Yen T, Harrison CA, Devery JM, Leong S, Iismaa SE, Yoshimura T $\&$ Geczy CL. Induction of the $\mathrm{S} 100$ chemotactic protein, CP-10, in murine microvascular endothelial cells by proinflammatory stimuli. Blood $1997904812-4821$.

37 Nisapakultorn K, Ross KF \& Herzberg MC. Calprotectin expression in vitro by oral epithelial cells confers resistance to infection by Porphyromonas gingivalis. Infection and Immunity 200169 4242-4247. (https://doi.org/10.1128/IAI.69.7.4242-4247.2001)

38 Kido J, Hayashi N, Kataoka M \& Nagata T. Calprotectin expression in human monocytes: induction by porphyromonas gingivalis lipopolysaccharide, tumor necrosis factor-alpha, and interleukin-1beta. Journal of Periodontology 200576 437-442. (https://doi.org/10.1902/jop.2005.76.3.437)

39 Hu SP, Harrison C, Xu K, Cornish CJ \& Geczy CL. Induction of the chemotactic $\mathrm{S} 100$ protein, CP-10, in monocyte/macrophages by lipopolysaccharide. Blood 199687 3919-3928.

40 Korkmaz H, Tabur S, Savas E, Ozkaya M, Aksoy SN, Aksoy N \& Akarsu E. Evaluation of serum S100A8/S100A9 levels in patients with autoimmune thyroid diseases. Balkan Medical Journal 201633 547-551. (https://doi.org/10.5152/balkanmedj.2016.15881)

41 Vogl T, Tenbrock K, Ludwig S, Leukert N, Ehrhardt C, van Zoelen MA, Nacken W, Foell D, van der Poll T, Sorg C, et al. Mrp8 and Mrp14 are endogenous activators of Toll-like receptor 4, promoting lethal, endotoxin-induced shock. Nature Medicine 200713 1042-1049. (https://doi.org/10.1038/nm1638)

42 O'Neill LA. The interleukin-1 receptor/Toll-like receptor superfamily: 10 years of progress. Immunological Reviews 2008226 10-18.

43 Dinarello CA. Blocking IL-1 in systemic inflammation. Journal of Experimental Medicine 2005201 1355-1359. (https://doi.org/10.1084/ jem.20050640)

44 Kemp EH, Metcalfe RA, Smith KA, Woodroofe MN, Watson PF \& Weetman AP. Detection and localization of chemokine gene expression in autoimmune thyroid disease. Clinical Endocrinology 200359 207-213. (https://doi.org/10.1046/j.13652265.2003.01824.x)

Received in final form 25 April 2018

Accepted 15 May 2018

Accepted Preprint published online 15 May 2018 http://www.endocrineconnections.org https://doi.org/10.1530/EC-18-0019 (c) 2018 The authors Published by Bioscientifica Ltd

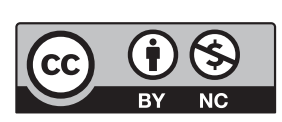

This work is licensed under a Creative Commons Attribution-NonCommercial 4.0 International License. 